When referencing please cite

Adair, D., Taylor, T., \& Darcy, S. (2010). Managing ethnocultural and 'racial' diversity in sport: Obstacles and opportunities. Sport Management Review, 13(4), 307312.

\title{
INTRODUCTION
}

\section{Managing ethnocultural and 'racial' diversity in sport: obstacles and opportunities}

Daryl Adair, Tracy Taylor and Simon Darcy

Diversity involves coming to terms with alterity (otherness) and negotiating inclusion (togetherness). That goal is more likely, philosopher Emmanuel Levinas argues, when people usually separated - socially culturally, politically, economically geographically - are brought together in consensual face-to-face contact and in social contexts where equitable interpersonal co-operation and group cohesion are fostered (Burggraeve, 2002; 2008). Such a quest for consensus about diversity and mutuality, as opposed to discordance through disdain for difference (Grillo, 2007), is a challenge (but also an opportunity) in a range of normative environments, such as business, education and sport (Kostogriz \& Doecke, 2007; Lim, 2007; Sykes, 2006). In an overarching sense, the management of diversity and the policies that underpin mutuality are arguably contributions to cosmopolitanism, which Vertovec and Cohen (2002, p. 4) argue incorporates 'variously complex repertoires of allegiance, identity and interest'. They conclude that cosmopolitanism, as an applied philosophical position, 'seems to offer a mode of managing cultural and political multiplicities' (2002, p. 4).

What of managing diversity, mutuality and cosmopolitanism in sport? During a 1994 keynote address, the American academic Joy DeSensi argued that there is a tremendous need for our sport management programs to make a commitment to reflect and directly address multicultural issues and education' (De Sensi, 1994, p. 63). Since then, questions about respect for diversity in sport, whether framed under concepts like multiculturalism, interculturalism, feminism or critical race theory, have become an increasingly significant component of activist sport management research (Cunningham \& Fink, 2006; Singer, 2005). 
However, while there have been important academic recommendations and policy initiatives to encourage diversity, both the conduct and management of sport have often been resistant to such cultural transformation (Cunningham, 2009). The domain of sport, whether at professional or community levels, and in various parts of the world, continues to be dominated by groups that wield the greatest power; sport, in this sense, still helps to perpetuate the marginalisation and subjugation of, for example, women, ethnic minorities and Indigenous people. Moreover, the policy rhetoric of cultural diversity has often not translated into sport management practice, with one or more of the aforementioned groups remaining marginalised or subordinated despite institutional goals of affirmative action and other equity-based reforms within sport (Cunningham, 2009; Singer, 2005; Spracklen, Hylton and Long 2006; Taylor \& Toohey, 1998; Taylor 2004).

There are also challenges for sport entities that are proactive in terms of diversity goals. As Taylor argues, these organizations 'must effectively manage' conflicts or differences that might arise during the implementation of diversity policies and therefore need to 'work to overcome ... miscommunication, stereotyping and prejudice, and the uncertainty and anxiety that may cause for all' (Taylor, 2008: 241). Sport diversity, in its broadest sense, therefore involves sound management principles, the creation of intercultural trust, and a commitment to build inclusive interpersonal environments. These are important at all levels of sport, from the board of directors to coaching staff and players, and from club volunteers through to spectators (Taylor, 2008).

This special issue of $S M R$ focuses on two inter-related, yet often separated themes in the management of diversity in sport - the socio-cultural domains of 'race' and ethnicity. The thematic volume was conceived in the wake of the conference Sport, Race and Ethnicity: Building a Global Understanding, which was staged by the University of Technology Sydney, 30 Nov - 2 Dec 2008. ${ }^{1}$ This symposium involved academics, practitioners and policy makers in three days of debate about sport as 'racial' and ethnic terrain, including discussions about opportunities and obstacles to sport being a site of diversity and inclusion, issues of ethno-racial discrimination and prejudice, and problems of ethno-racial stereotyping in respect of athletic performance. The first four articles of this SMR volume emerged directly

\footnotetext{
${ }^{1}$ For details see http://www.business.uts.edu.au/lst/sre/.
} 
from papers presented at the Sport, Race and Ethnicity conference; they showcase new research into the experiences of Aboriginal people and ethnic minorities in sport, and also feature the critical co-theme of gender. These papers are ideally supplemented by cutting edge articles that address sport and diversity in the North American context - particularly in respect of African American experiences. In short, the papers in this $S M R$ edition, when taken as a whole, provide the reader with an opportunity for broadly based reflections about sport management and societal structures, values, norms and policies in the context of what might be termed ethnoracial studies (Richomme, 2009).

This dual engagement of 'race' and ethnicity widens the scope of analysis, but it also presents challenges, such as contention about what these descriptors represent, and their complex and often contradictory relationship (Adair \& Rowe, 2010). For example, there is a widespread view that there is no scientific basis to 'race', hence the qualifier 'race' is sometimes highlighted to emphasise the social constructedness of this term and, therefore, the fallacy of biological determinism (Graves, 2001, pp. 1-7). 'Race', in this sense, is simplistically applied to skin colour and stereotypical assumptions about identity and status associated with racialized appearance. Despite its flaws, 'race' has currency in social practice; as Warmington has put it, 'the paradox of race-conscious scholarship' (2009, p. 281) lies in the need to work within, yet against, problematic conceptual tools.

Ethnicity, meanwhile, has fundamental links with ancestry but not biology: family, language, religion and nationality are key bases for ethnic identity. Individuals are born into ethnic communities but may reject this connection, recasting themselves with a different sense of self. Ethnicity, therefore, seems more fluid than 'race'; racialized individuals are categorised socially as 'Black', 'White', and so on, but are not at liberty to reinvent themselves in terms of skin colour (Cornell \& Hartmann, 2007, p. 39). That said, physical appearance is hardly the sole barometer of 'race'; some individuals, while fair-skinned in appearance, claim for themselves a 'racial' identity that connotes blackness, or at least non-whiteness, such as with a small, but significant minority of Indigenous Australians. Aboriginal identity is complex in another way: many Indigenous Australians have links to one or more ancestral tribes with distinctive languages and customs; they are, therefore, ethnically divergent despite being typecast in popular thought as homogeneous - 
whether in terms of 'race' or Aboriginality (Cowlishaw, 1987; Tomkinson, 2001; Paradies, 2006).

These brief illustrations underscore the difficulty of relying on 'race' and/or ethnicity as exclusive social categories; related descriptors such as Indigeneity, diaspora and creolization may be equally important in particular contexts (Brubaker, 2005; Paradies, 2006; Cohen and Toninato, 2009). The academic literature has, in short, featured a move away from essentialism and towards hybridity and fluidity, a flexible, radically contextual approach coinciding with - though by no means confined to - the influence of postmodernist perspectives and postcolonial critiques (Adair \& Rowe, 2010). Ethno-racial scholarship in sport management has, as the following papers indicate, begun to reflect this embrace of conceptual complexity and methodological elasticity.

Thomson, Darcy and Pearce's ambitious study of Australian third sector organization's approaches to sports development programs with Aboriginal and Torres Strait Islander youth brings together dominant cultural traditions in sports development and Indigenous approaches. It does so through Ganma, a theory belonging to the Yolngu community of Yirrkala (Marika, Ngurruwutthun, \& White, 1992) that literally means the bringing together of two bodies of water to mutually engulf each other. Within this lens, five cultural and philosophical considerations are regarded as important to understand inclusive programs. They are: that culture is living and dynamic; across the Australian continent there is heterogeneity of cultures (whether Indigenous or non-Indigenous); kinship and spirituality underpin Indigenous considerations; Indigenous representation needs to be considered within and of the development program; and the impact of experience includes both moving with Indigenous people and acknowledging their history.

Three comparative case studies were purposively selected, the commonality between them being both a recognition and inclusion of cultural considerations at all levels, even though the activities varied from elite professional development, sport role models and community based sport competition. The case studies identified challenges within the governance and approach to sport development used by each of the third sector organizations. Two of the organizations were run by Aboriginal and 
Torres Strait Islanders with further input through the boards and committees. The other organization was run by a non-Indigenous Australian with board involvement; it involved the employment of a cultural adviser, and sought to engage with Aboriginal people. While two of the programs took place within Indigenous communities, the other elite development program brought youth from all over Australia to a central point for athletic competition; and, if selected, to a major urban centre for concentrated sport development within a residential setting supported by Indigenous house parents. The implications for sports management are that while there is no one approach to either governance or sport development, organizations need to engage deeply with underlying cultural considerations before connecting with Indigenous peoples. Organizational engagement needs to be strategically planned, deeply committed, prolonged, and focused on community development in order to empower and sustain sport activity.

Palmer \& Masters present a Māori feminist intersectionality perspective to examine the voices of four women sport leaders. In particular, the paper presents the intersection between the ethnocultural and gendered identities of the Māori women and the influence this has on pathways into and within sport, as well as the affects these have on their leadership styles. The research design invited four women who self-identified as Māori and had roles within sport organizations, to participate in semi-structured, kanohi $k i$ te kanohi (face-to-face) interviews. The resulting conversations examined the barriers that the women confronted and the strategies they used to negotiate barriers to their sport involvement, as well as the creation of leadership roles they took up within sport organizations. What becomes apparent is that these Māori women have a series of identities that are drawn upon at different stages of their sporting lives and as administrators within sport organizations. These identities are a result of three combined structural factors: their Māori cultural background, their identities and roles as women, and their positions within sport organizations.

The major contribution of the paper is its poignant understanding of the complex Māori ethnocultural considerations that these women traverse. Palmer \& Masters eloquently communicate these considerations using Māori language and concepts; they explain the implications these have for the women, the leadership approaches they take, and their application to a sport organization context. They 
demonstrate that the sport management environment can be conducive to the coengagement of Māori women and their culture. Mana (status and prestige) is attached to elite engagement in sport and enhanced through the leadership roles that the women take up. Yet, for them, leadership is more than just the trappings of individual success; it is deeply entwined within mahi aroha where giving back to community is central to their responsibility to sport and their Māori communities. Not surprisingly, the Māori cultural context also influences their particular leadership style, which was characterized by a partnership approach that challenges ethnocultural and gendered expectations within the largely male-dominated, competitive world of sport. This manifested within the leadership styles through a combination of whanaungatanga (kinship), manaakitanga (support) and aroha (compassion).

Palmer \& Masters conclude by suggesting that sport organizations can incorporate a quadruple bottom line (economic, environmental, social and cultural measures of business success) where cultural considerations become the fourth consideration to understanding organizational success. Like the paper by Thomson, Darcy \& Pearce, understanding the Indigenous cultural context is crucial to sport engaging with Aboriginal people and also in terms of Indigenous people feeling welcome within sport as participants, volunteers, officials or spectators. By gaining a deeper understanding of Indigenous cultural considerations, both the individuals from Indigenous backgrounds and the sport organizations they engage with will benefit.

In the third paper featuring Indigenous perspectives, Larena Hoeber provides insights into two important considerations for sport management, that of volunteers and the Aboriginal community in Canada. Volunteers are a resource under pressure in Western nations globally, and, as other papers in this edition make evident, Indigenous engagement and cultural diversity are areas where sport organizations have yet to realize the full potential of the communities in which they operate. Hoeber provides a qualitative re-analysis of the experience of Aboriginal volunteers through two studies: the first provided an understanding of Aboriginal individuals who volunteered for Aboriginal and non-Aboriginal sporting organizations through nine focus groups; and the second, with Aboriginal individuals who volunteered at one of two multi-sport events through five focus groups. The re-analysis used manual 
coding for the dimensions of intended beneficiaries, structure, remuneration and free choice as outlined by Cnaan, Handy, \& Wadsworth (1996).

Hoeber's examination of Aboriginal experiences challenges a typical mainstream Canadian understanding of volunteering where these voices have been largely unrecognized. Her findings suggest that the individuals in the study valued their contribution to their Aboriginal communities and, in particular, the opportunity to provide a guiding influence to Aboriginal youth. As such, the beneficiaries were these locals, and so the volunteers' engagement can be seen as part of a broader collective responsibility to help their communities through the vehicle of sport. Consequently, there was little mention or discussion of 'free choice' as a consideration. While volunteers' engagement was formalized through an organization or events structure, the roles they took within them were relatively unstructured; they valued a laid-back environment where fun was an important element. Dominant human resource management practices needed to be modified to meet Aboriginal traditions. For example, cultural custom led to the payment of Indigenous volunteers. The practice may have arisen from the custom of gift giving for those who share their knowledge, particularly Elders in Aboriginal communities. As Hoeber contends, this practice of recognizing volunteers, together with sport organizations helping locals with valued projects, may be a way to help redress socio-economic disadvantage within these communities.

Overall, these three papers on Indigenous contributions to sport suggest that this work has only just begun to go beyond the compliance requirements of human rights conventions and antidiscrimination legislation to deeply understand Indigenous cultural considerations and how they can be harnessed in order to properly value Aboriginal people and, in turn, to develop more culturally inclusive and socially sustainable organizational practices within sport.

Another significant group in terms of diversity management and policy in sport is migrants - particularly those who come from places where the language and culture are very different to that of their new domain. This is a theme taken up by Pooja Sawriker and Kristy Muir, who are interested in sport participation among culturally and linguistically diverse women in Australia. Their article, which is part of a wider study, examines perceptions about, and experiences of, sport for Indian 
women, and reflects upon how the responses of this group compares to those of other females in Australia from a non-English speaking background. The authors conducted focus groups in three states and, in respect of the Indian cohort, engaged a group of seven women in Sydney. They pursued the question of why ethnic minority women in Australia generally have lower levels of sport participation than other females. They found that, among the Indian subjects, there was no lack of interest in sport participation. Rather, they faced a range of constraints that diminished their opportunity to take part in organized physical activity. Some of these are typical of women generally, such as gender-specific norms about female responsibilities in respect of child rearing and housekeeping, this leaving little time for discretionary leisure - particularly when the women were also engaged in outside work. Other constraints were more culturally specific, such as Indian women being criticized by their extended families for undertaking sport activities that contravened traditional norms.

Interestingly, none of the Indian participants in the study had experienced discrimination or racism while taking part in Australian sport. However, those who had yet to become engaged in sport felt a certain trepidation; namely, that they did not suit the dominant media stereotype of blonde-haired, physically dexterous Australian women athletes. This suggested a lack of confidence which, Sawriker and Muir argued, could be countered by a greater commitment from those in sports media to showcase women from various cultural backgrounds in sport. Just as important, concluded the authors, was the establishment of links between sport organizations and culturally and linguistically diverse communities. They therefore suggested the deployment of a 'buddy system', whereby individuals within sport organizations committed to widening the cultural base of their club by inviting women from various backgrounds in sport, helping them to become familiar with the rules and conventions of their sport, and working with them to feel comfortable in new surroundings. After all, Sawriker and Muir conclude, if the Indian cohort is any guide, there is plenty of latent demand among migrants to become involved in sport in Australia.

College sport in the United States has no peer worldwide, whether in terms of scale, scope or profile. American universities are not only places of teaching and research, they also feature NCAA sport teams that attract enormous public interest, 
not only from students and alumni but also the general public. Coaches of college football and basketball, for example, are paid very lucrative salaries and these sports produce considerable income for various stakeholders - except, of course, for the athletes, all of whom are expected to be amateur. Even so, for many budding elite athletes, college sport is the pathway to a professional career, with the NBA draft, for example, recruiting directly from NCAA teams and university graduates. In this rarefied atmosphere of high performance athleticism, questions about access and opportunity to engage in college sport - whether as players or coaches - are profoundly powerful. Within that milieu, debates about ethno-racial diversity continue to resonate, as Doherty et al, Carter and Hart, Cunningham, and Borland and Bruening explain in this issue of $S M R$.

Through their paper in this special issue, Alison Doherty, Janet Fink, Sue Inglis and Donna Pastore, explore perceptions and experiences of organizational culture and diversity by interviewing eleven personnel in athletic departments at NCAA Division III institutions. They outline a paradox: in American college sport there has been a lack of cultural diversity in key positions such as head coach and athletic director, yet management research suggests that there are important benefits to organizations - whether in sport or business - that embrace different ideas, insights, values and perspectives as a consequence of engaging suitably qualified people from ethno-racial minorities. Determined to investigate this status quo, and to theorise how it might be challenged, the authors conducted in-depth interviews with individuals working in university athletic departments. They also developed a theoretical framework that incorporated concepts of power, transformation and forces for/against change; this not only shaped the nature of their semi-structured interviews, it also provided analytical themes through which to organise findings. In brief, the authors concluded that a culture of diversity in athletic departments is impacted upon by a complex interplay of both driving and resisting forces, as well as combinations of what they describe as deep and surface level power. The overarching implication of the study is that athletic departments ought to be trying to strengthen forces that drive diversity and reduce forces that either constrain or oppose diversity.

Continuing a focus on sport in American universities, Akilah Carter and Algerian Hart investigate the concept of mentoring and the experiences of Black female USA collegiate athletes within predominantly White institutions. Noting the 
positive outcomes that mentoring student-athletes can achieve, Carter and Hart apply a critical feminist framework to expose the 'multiple jeopardies' of the particular situations of Black female athletes. They highlight the importance of employing a research method that promotes social justice and an emanicipatory aspect for research participants/ informants that have been historically marginalized.

The ideal mentor, the authors argue, should be able to lead the mentee through life difficulties and provide sage advice in relation to career/academic support, emotional and social support, and athletic support. The multiple jeopardies of race, gender, class, and athletics/sport experienced by the Black female athlete, necessitates the choice of mentors that are cognizant and competent to the experiences of mentee. The study's finding that many Black female USA collegiate athletes have family members as their mentors lead the authors to raise concerns that these women might not have access to some of the benefits of a traditional mentor and protégé relationship, such as trust, a vision for the future, professional skills and confidence, and networking with influential persons.

Carter and Hart call on sport administrators to recognise the unique situation of the student athlete mentee when providing support services and developmental programs, and to provide appropriately tailored structured mentorship programs. Given the intensely individual dimension of mentoring and the nature of the trust relationship that is core to mentor-mentee association, the recommendations of this study could have general applicability to all athletes. Research into the nature and benefits of mentoring in the corporate world is replete, however there is scant literature on the role of mentoring in the nuanced sport 'workforce'. We therefore hope that this study spurs others to further delve into the roles that mentoring can play in assisting individuals to reach their full potential in their sport career.

George Cunningham's article on race, diversity and coaching is also situated within the US collegiate athletics domain. It charts how we can use a multilevel framework to better understand the under-representation of African-Americans as coaches of university athletic teams. Cunningham provides evidence of continuing racial prejudice and discrimination in coaching and notes that much of the previous research in this area has been limited by a focus on a single level of analysis. 
Cunningham suggests that macro-level institutionalised practices, the political climate of the organisation, stakeholder expectations; in conjunction with those factors operating at meso-level prejudice on the part of decision makers, discrimination, leadership prototypes, organisational culture of diversity are intertwined with micro-levels aspects of head coaching expectations and intentions, occupational turnover intentions. These factors are simultaneously present at multiple levels and each can subsequently influence the outcomes of another. The framework presented articulates how all the factors taken together affect whether or not an African American obtains a head coaching position and how, why, and when these factors exert their influence.

For sport to become truly inclusive, policy development and change cannot just focus on a single level and must take into account the intersectionality of macro-, meso-, and micro-level factors. Cunningham provides us with an illustration of how change might be initiated by outlining steps taken by the NCAA to address the factors present at each of these levels. The paper concludes with a call to action that should resonate with everyone working in sport, as it requires all of us to get on board to ensure that sport becomes a space characterised by diversity and inclusion.

John Borland and Jennifer Bruening continue the scrutiny of diversity and race in the US collegiate athletics domain through an exploration of the underrepresentation of Black females as coaches. Taking an intersectionality approach they sought to identify barriers contributing to the under-representation of Black women in head coaching jobs in Division I women's basketball; their strategy was to interview Black female assistant basketball coaches working at predominantly 'White' Division I institutions.

Access discrimination, lack of support, and prevalent stereotypes were identified as critical barriers, whilst successful negotiation through these barriers could be achieved when women engaged in extensive networking, mentoring and presenting an appropriate image for athletics. The women interviewed suggested that for change to occur an expansion of job pools, more mentoring by athletic department personnel, and more development programs offered for young Black females were required. In particular, the mentoring aspect could be followed up with reference to the recommendations made in Carter and Hart's contribution. The 
authors also highlight the heterogeneity focus of sport research, the scarcity of research on the experiences of Black sportswomen and other under-represented groups in sport, such as Asians and Hispanics, and that there is an urgent need for more studies of this kind. ${ }^{2}$

Finally, James Allen, Dan Drane, Kevin Byon and Richard Mohn explore an area of sport and diversity management that has hitherto been analyzed too rarely the sport activity needs and experiences of international students attending American universities. The authors used a survey instrument to garner data from 240 respondents; this quantitative approach also involved the development of a new investigative scale. Preliminary findings, which will be supplemented by further research, suggest that international students who engage in sport at US colleges typically adapt to the sport environment presented to them, rather than use sport as a means of reinforcing their traditional sense of culture and identity. However, this may have more to do with available sport resources and the physical activity logistics of American colleges. The authors argue that universities with more than a 10\% proportion of international students ought to develop sport facilities that meet the cultural needs of this cohort, such as the provision of cricket facilities for students from India or Pakistan. Allen et al argue that this could also benefit American students, opening them up to sports considered 'minor' in the US, while also providing a basis by which local and international students could develop sociocultural rapport.

As editors of this special issue of $S M R$ our final word is of thanks; to the authors and referees who made this volume possible, and to the SMAANZ editorial board for providing us with the opportunity to oversee the production of a significant contribution to debates about ethnocultural and 'racial' diversity in sport management.

Daryl Adair, Tracy Taylor and Simon Darcy

\section{References}

2 Importantly, a special issue on race and ethnicity is currently being prepared for the Journal of Sport Management under the editorship of Dr Ketra L. Armstrong. 
Adair, D. and Rowe, D. (2010) Interrogating Boundaries of 'Race', Ethnicity, and Identity. International Review for the Sociology of Sport (in press).

Brubaker, R. (2005). The 'Diaspora’ Diaspora, Ethnic and Racial Studies, 28 (1): 1-19.

Burggraeve, R. (ed.), (2002). The wisdom of love in the service of love: Emmanuel Levinas on justice, peace, and human rights, (trans. Jeffrey Bloechl). Milwaukee: Marquette University Press.

Burggraeve, R. (ed.), (2008). The awakening to the other: a provocative dialogue with Emmanuel Levinas, Leuven: Peeters.

Cnaan, R. A., Handy, F., \& Wadsworth, M. (1996). Defining who is a volunteer: Conceptual and empirical considerations. Nonprofit and Voluntary Sector Quarterly, 25(3): 364-383.

Cohen, R. and Toninato, P. (eds), (2009). The creolization reader: Studies in mixed identities and cultures, London: Routledge.

Cornell, S. and Hartmann, D. (2007). Ethnicity and race: Making identities in a changing world, Thousand Oaks CA: Sage, $2^{\text {nd }}$ edition.

Cowlishaw, G. (1987). Colour, Culture and the Aboriginalists, Man (new series), 22 (2): 22137.

Cunningham, G.B. (2009). Understanding the Diversity-Related Change Process: A Field Study, Journal of Sport Management, 23: 407-28.

Cunningham, G.B. and Fink, J.S. (2006). Diversity Issues in Sport and Leisure, Journal of Sport Management, 20(4): 455-65.

DeSensi, J.T. (1994). Multiculturalism as an Issue in Sport Management, Journal of Sport Management, 8: 63-74.

Graves, J.L. Jr. (2001). The emperor's new clothes: Biological theories of race at the milennium, Piscataway NJ: Rutgers University Press.

Grillo, R. (2007). An Excess of Alterity? Debating Difference in a Multicultural Society. Ethnic and Racial Studies, 30 (6): 979-998.

Kostogriz, A. \& Doecke, B. (2007). Encounters With 'Strangers': Towards Dialogical Ethics in English Language Education. Critical Inquiry in Language Studies, 4 (1): 1-24.

Lim, M. (2007) The Ethics of Alterity and the Teaching of Otherness. Business Ethics: A European Review, 16 (3): 251-263.

Marika, R., Ngurruwutthun, D., \& White, L. (1992). Always together, yaka gana: Participatory research at yirrkala as part of the development of a yolngu education. Convergence (International Council for Adult Education), 25(1), 23-41. 
Paradies, Y.C. (2006). Beyond Black and White: Essentialism, Hybridity and Indigeneity, Journal of Sociology, 42 (4): 355-67.

Richomme, O. (2009). The Role of 'Ethno-Racial' Classification in the Americanization Process, Cercles. 19: 1-18.

Singer, J.N. (2005). Addressing Epistemological Racism in Sport Management Research. Journal of Sport Management, 19: 464-79.

Spracklen, K., Hylton, K. and Long, J. (2006). Managing and Monitoring Equality and Diversity in UK Sport: An Evaluation of the Sporting Equals Racial Equality Standard and Its Impact on Organizational Change. Journal of Sport \& Social Issues. 30 (3): 289-305.

Sykes, H. (2006). Transsexual and Transgender Policies in Sport. Women in Sport and Physical Activity Journal, 15: 3-13.

Taylor, T. (2004). The Rhetoric of Exclusion. Journal of Sport \& Social Issues, 28 (4): 45376.

Taylor, T. (2008). Managing people in sport organizations. Oxford: ButterworthHeinemann.

Taylor, T. and Toohey, K. (1998). Negotiating Cultural Diversity For Women in Sport: From Assimilation to Multiculturalism. Race Ethnicity and Education, 1 (1): 75-90.

Tonkinson, M.E. (2001), Is it in the Blood? Australian Aboriginal Identity, in Linnekin, J. and Pyer, L. (eds), Cultural identity and ethnicity in the Pacific. Honolulu: University of Hawaii Press (paperback edition): 191-218.

Vertovec, S. and Cohen, R. (eds), (2002). Concieving cosmopolitanism: Theory, context and practice, Oxford: Oxford University Press.

Warmington, P. (2009). Taking Race Out of Scare Quotes: Race-Conscious Social Analysis in an Ostensibly Post-Racial World, Race, Ethnicity and Education, 12 (3): 281-96. 